\title{
Weight, gender, and snack appeal
}

Citation for published version (APA):

Havermans, R. C., Giesen, J. C. A. H., Houben, K., \& Jansen, A. (2011). Weight, gender, and snack appeal. Eating Behaviors, 12(2), 126-130. https://doi.org/10.1016/j.eatbeh.2011.01.010

Document status and date:

Published: 01/01/2011

DOI:

10.1016/j.eatbeh.2011.01.010

Document Version:

Publisher's PDF, also known as Version of record

Document license:

Taverne

Please check the document version of this publication:

- A submitted manuscript is the version of the article upon submission and before peer-review. There can be important differences between the submitted version and the official published version of record.

People interested in the research are advised to contact the author for the final version of the publication, or visit the DOI to the publisher's website.

- The final author version and the galley proof are versions of the publication after peer review.

- The final published version features the final layout of the paper including the volume, issue and page numbers.

Link to publication

\footnotetext{
General rights rights.

- You may freely distribute the URL identifying the publication in the public portal. please follow below link for the End User Agreement:

www.umlib.nl/taverne-license

Take down policy

If you believe that this document breaches copyright please contact us at:

repository@maastrichtuniversity.nl

providing details and we will investigate your claim.
}

Copyright and moral rights for the publications made accessible in the public portal are retained by the authors and/or other copyright owners and it is a condition of accessing publications that users recognise and abide by the legal requirements associated with these

- Users may download and print one copy of any publication from the public portal for the purpose of private study or research.

- You may not further distribute the material or use it for any profit-making activity or commercial gain

If the publication is distributed under the terms of Article $25 \mathrm{fa}$ of the Dutch Copyright Act, indicated by the "Taverne" license above, 


\title{
Weight, gender, and snack appeal
}

\author{
Remco C. Havermans *, Janneke C.A.H. Giesen, Katrijn Houben, Anita Jansen \\ Maastricht University, Maastricht, The Netherlands
}

\section{A R T I C L E I N F O}

\section{Article history:}

Received 18 August 2010

Received in revised form 11 November 2010

Accepted 17 January 2011

Available online 25 January 2011

\section{Keywords}

Appetite

Approach-avoidance

Dietary restraint

Gender

Obesity

\begin{abstract}
A B S T R A C T
In this study, we hypothesized that overweight/obese persons have an exaggerated approach tendency toward high calorie foods. Testing this hypothesis, a stimulus response compatibility (SRC) task was used to assess approach-avoidance tendencies toward food in both overweight/obese participants $(n=42)$, and normal weight controls $(n=46)$. The SRC task is a reaction time task measuring how fast one approaches and avoids pictures of food and non-foods according to given instructions. It was found that overweight/obese men are slower at avoiding particularly high calorie snack foods. But this does not appear to be the case for overweight/obese women who showed nearly as fast avoidance as approach toward the high calorie food cues. It is concluded that overweight/obese women, rather than men, are ambivalent toward high calorie foods, which is the likely result of high dietary restraint.
\end{abstract}

(c) 2011 Elsevier Ltd. All rights reserved.

\section{Introduction}

The prevalence of overweight/obesity continues to rise worldwide and whether or not this should be termed an epidemic (or even pandemic), severe obesity poses a serious health risk (see e.g., Olshansky et al., 2005). Obesity results from a positive energy balance; energy intake exceeding energy expenditure (Jéquier, 2002). At least from a health perspective, maintaining or losing weight is important and one of the most popular methods for weight regulation is dietary restraint. Though popular it is notoriously hard to maintain a low calorie diet and thus any achieved weight loss is difficult to uphold on the longer term (Wing et al., 2008). Indeed, dieting attempts appear associated with future weight gain, not weight loss (Lowe et al., 2006; Stice, Agras, \& Hammer, 1999; Stice, Cameron, Killen, Hayward, \& Taylor, 1999).

Why does dieting so often fail? According to Lowe and Levine (2005), food intake is governed by physiological needs and hedonic eating motives. In most Western societies where food is abundant, daily eating behaviour is likely determined by hedonic motivations, that is, reward-driven eating or the desire to eat highly palatable foods. Due to the interplay between an innate sweet/fat preference and the rapid acquisition of strong preference for especially flavours that signal energy (Havermans \& Jansen, in press), the most palatable foods for most people are typically high energy dense foods. Indeed, exposure to such energy dense palatable foods not only induces a strong desire to eat, it does so even in the absence of hunger.

\footnotetext{
* Corresponding author at: Maastricht University, Faculty of Psychology \& Neuroscience, dept. Clinical Psychological Science, PO Box 616, 6200 MD Maastricht, The Netherlands. Tel.: + 31433884053.

E-mail address: r.havermans@maastrichtuniversity.nl (R.C. Havermans).
}

Unsurprisingly then, palatability has been found to be a strong determinant of meal intake, regardless of one's momentary homeostatic needs (Yeomans, Blundell, \& Leshem, 2004). This 'hedonic hunger' (cf. Lowe \& Levine) encourages eating beyond energy needs, and hence can promote weight gain. However, the hedonic appeal of a high calorie food does not appear to be equal for all individuals. For example, both restrained eaters and overweight/obese persons, relative to controls, are more prone to work for high calorie snacks (Giesen, Havermans, Douven, et al., 2010; Giesen, Havermans, \& Jansen, 2010; Giesen, Havermans, Nederkoorn, Strafaci, \& Jansen, 2009). Successful weight loss or the prevention of excessive weight gain is often thought to hinge on the ability to suppress a hedonic eating motive (see e.g., Appelhans, 2009; Stroebe, Papies, \& Aarts, 2008). Conceivably, this is all the more difficult if this appetitive motivation for palatable high calorie food is particularly strong. According to this line of reasoning one would expect that overweight/ obese individuals show an exaggerated approach tendency for especially high calorie foods. Indeed, Brignell, Griffiths, Bradley, and Mogg (2009), using a stimulus-response compatibility (SRC) task, demonstrated that 'overeaters' (as based on their score on the 'external eating' scale of the Dutch Eating Behavior Questionnaire) show a relatively exaggerated approach bias toward food cues.

The SRC task was originally designed by De Houwer, Crombez, Baeyens, and Hermans (2001). Participants have to direct a manikin toward or away from a stimulus presented in the centre of a computer screen depending on given instructions. The supposition is that one is faster to approach liked stimuli and to avoid disliked stimuli than one is to approach disliked stimuli and to avoid liked stimuli (Krieglmeyer, Deutsch, De Houwer, \& De Raedt, 2010). In the SRC task employed by Brignell et al. (2009), participants had to move the manikin either toward or away from pictures related to either food or something other 
than food. The high-external eaters, relative to the low-external eaters, were significantly faster to move the manikin toward the food pictures (and away from the non-food related cues) than they were to move the manikin away from the food cues (and toward the non-foods) (see also Veenstra \& de Jong, 2010). Although interesting, it remains to be determined whether overweight/obese individuals too display this excessive approach tendency for food and if so, whether this is more or less limited to high calorie snack foods. For the present study, we hypothesized that overweight/obese persons display a stronger approach bias toward specifically high calorie foods than normal weight controls do. To test this hypothesis we employed an SRC task very similar to the task used previously by Brignell et al. (2009).

\section{Method}

\subsection{Participants}

Eighty-eight undergraduate students from Maastricht University were invited to take part in a study on choice behaviour and mental fatigue. They in fact took part in two separate experiments: the present study and another study using a behavioural task to measure the relative reinforcing value of snack food, results of which are reported elsewhere (see Giesen, Havermans, Douven, et al., 2010).

Students were invited to take part on the basis of self-reported Body Mass Index (BMI; $\mathrm{kg} / \mathrm{m}^{2}$ ). We strived to create two weightdiscordant groups by selecting candidate participants with a selfreported $\mathrm{BMI} \geq 25$ and an equal number of students with a selfreported $\mathrm{BMI}<25$ (preferably around 20). Participants' BMI was measured at the end of participation and the final assignment of participants to either the overweight/obese condition or the normal weight condition was determined on the basis of these actual BMIs. Participants with a BMI $\geq 25$ were classified as overweight $(n=29$; BMI range: 25.2-29.6) or obese ( $n=13$; BMI range: 30.6-36.6), participants with a BMI between 18 and 25 were classified as normal weight. General participant characteristics for each separate group (overweight/obese vs. normal weight) are displayed in Table 1.

\subsection{Materials and measurements}

\subsubsection{Hunger}

Participants rated their momentary hunger on a $100 \mathrm{~mm}$ Visual Analogue Scale (VAS) ranging from 0 "not at all hungry" (left anchor) to 100 "very hungry" (right anchor).

\subsubsection{Stimulus response compatibility (SRC) task}

The task the participants had to perform was adapted from the SRC task described by Thewissen, Havermans, Geschwind, van den Hout, and Jansen (2007) and was programmed in E-prime (Psychology

Table 1

Mean age, BMI, hunger ratings, TFEQ factor scores, and the ratio of male to female participants per group (normal weight vs. overweight/obese).

\begin{tabular}{|c|c|c|c|}
\hline \multirow[t]{2}{*}{$N$} & \multirow{2}{*}{$\frac{\text { Normal weight }}{46}$} & \multirow{2}{*}{$\frac{\text { Overweight/obese }}{42}$} & \\
\hline & & & \\
\hline Age (years) & $19.4(1.4)$ & $20.3(3.7)$ & $t(86)=1.62, n s$ \\
\hline Gender ratio & $\begin{array}{l}25 \text { men/21 } \\
\text { women }\end{array}$ & $\begin{array}{l}19 \text { men/23 } \\
\text { women }\end{array}$ & $\chi^{2}=.73, n s$ \\
\hline BMI & $22.2(1.4)$ & $28.9(2.9)$ & $t(86)=13.99, p<.001$ \\
\hline Hunger & $57.5(21.5)$ & $49.6(19.6)$ & $t(86)=1.80, p=.075$ \\
\hline TFEQ-hunger & $4.7(2.3)$ & $4.5(2.5)$ & $t(86)=0.48, n s$ \\
\hline TFEQ-disinhibition & $5.0(2.4)$ & $6.5(2.4)$ & $t(86)=2.79, p=.007$ \\
\hline TFEQ-restraint & $4.7(3.2)$ & $7.7(4.5)$ & $t(86)=3.66, p<.001$ \\
\hline
\end{tabular}

Note. Values enclosed in parentheses represent SD and 'ns' denotes non-significance (i.e., $p>.10)$.
Software Tools, Inc). The task comprised two blocks of 80 trials. In each trial, either a $160 \mathrm{~mm}$ high $\times 215 \mathrm{~mm}$ wide food picture $(10$ different food pictures were used; e.g., a picture of chocolate cookies, grapes, crisps, et cetera) or a neutral picture (10 different neutral nonfood pictures were used; e.g., a wooden shoe, a traffic cone, a cardboard box, et cetera) was displayed at the centre of the screen together with a manikin (an approximately $18 \mathrm{~mm}$ high $\times 10 \mathrm{~mm}$ wide matchstick figure) placed exactly between the outer border (either the upper or lower border) of the picture and the edge of the screen.

Each block of trials had a different stimulus response assignment. In one block the participants were instructed to approach the food pictures with the manikin by using the up- or down arrow keys depending on the starting position of the manikin, and to avoid the neutral picture by moving the manikin away from the picture outside the screen. The following trial was initialized upon completion of the correct response (i.e., approach or avoidance) and the time to complete each trial was recorded (in ms). A correct response required a minimum of five consecutive key presses. In the other block, participants received the instruction to avoid the food pictures and to approach the neutral pictures as quick as possible. The order of these two blocks and the eight different trial types (position [above or below] $\times$ picture [food vs. neutral] $\times$ instruction [approach vs. avoid]) per block was determined randomly for each separate participant.

The task was preceded by a practice session that comprised two blocks of 16 trials each. In one block they had to approach pictures depicting a chair and to avoid pictures displaying a lamp. This stimulus response assignment was reversed for the other block.

With an SRC task, Brignell et al. (2009) assessed food approach/ avoidance tendencies and found that an approach bias was positively correlated with food pleasantness ratings and an attention bias for food as measured with a visual probe task. Van Gucht, Vansteenwegen, Van den Bergh, and Beckers (2008) showed that variations in subjective craving for chocolate within individuals covary with automatic chocolate approach tendencies as assessed with an SRC task. These studies suggest that the task is a valid measure for the indirect assessment of (at least a component of) the reward value of food cues.

\subsubsection{Three Factor Eating Questionnaire}

We employed a Dutch translation of the Three Factor Eating Questionnaire (TFEQ; Stunkard \& Messick, 1985) comprising 51 items pertaining to dietary restraint (i.e., the intention to control body weight by restricting one's food intake), disinhibition, or hunger susceptibility. This questionnaire more broadly pertains to the concept of 'restrained eating', the tendency to restrain food intake in order to control one's body weight. The TFEQ has good internal consistency (Stunkard \& Messick) and individual scores on its three factors have demonstrated it to be stable even over long periods of time (i.e., approximately 6 years) as evidenced by significant positive test-retest correlations (see Drapeau et al., 2003). Further, it has proven to be a sensitive instrument in discriminating between dieters and non-dieters (French, Jeffery, \& Wing, 1994; Laessle, Tuschl, Kotthaus, \& Pirke, 1989).

\subsection{Procedure}

The experiment was approved by a local ethical committee. Participants were instructed to eat $2 \mathrm{~h}$ prior to the experiment and from that time on to refrain from food until participation. Participants were tested individually between noon and $6 \mathrm{PM}$. The experiment started with a brief verbal description of the general procedure of the experiment. After this, all participants also received written information regarding the experiment and were asked to sign a consent form if they still wished to participate.

The participant was asked to rate his degree of momentary hunger on a VAS, after which s/he first completed a task designed to assess the 
reinforcing value of a given snack food relative to the value of a fruit or vegetable alternative. Participants had to work for their highest liked snack food and their highest liked low calorie food (i.e. fruit or vegetable). Throughout the task the work effort required for snack food was gradually increased, thus allowing us to determine the relative motivation to work for or acquire high calorie snack foods. The task procedure is described in detail by Giesen, Havermans, \& Jansen (2010). This task was generally completed within $20 \mathrm{~min}$ and note that any 'earned' food was consumed only after the completion of both this so termed concurrent schedules task and the SRC task.

Upon completion of the SRC task, the participant was further asked to fill out the TFEQ. At the end of the study, the participant's height and weight was measured to calculate actual BMI. The participant was then thanked and received either a course credit or a $€ 7.50$ monetary voucher as remuneration.

\subsection{Data reduction and analyses}

All analyses concerned the participants' response time latencies to the different trial types and stimulus response assignments in the SRC task. To remove outliers, reaction times were excluded per participant and per trial type if they were smaller than 200 ms or larger than 2.5 SD above the mean RT (10\% of the data) (see also Thewissen et al., 2007).

\subsubsection{Weight, gender, and food approach/avoidance}

To assess whether overweight/obese participants show a stronger food approach bias than the normal weight participants do, response times for each participant (food approach vs. food avoidance) were averaged for the food approach assignment and the food avoidance assignment. These averaged RTs then served as the dependent variable in a 2 (Group: overweight/obese vs. normal-weight) $\times 2$ (Gender: male vs. female) $\times 2$ (Assignment: food approach vs. food avoidance) ANCOVA with hunger ratings as a covariate. Hunger ratings were entered as a covariate because hunger likely plays a role in food approach-avoidance tendency and the degree of self reported hunger seemed to differ at least marginally significant between the overweight/obese ( $\left.M_{\text {VAS hunger rating }}=49.6\right)$ and the normal weight participants $\left(M_{\text {VAS hunger rating }}=57.5\right)$ (see also Table 1$)$. Likewise, we added Gender as a factor to the analyses to control for any potential gender differences in food approach-avoidance tendency.

\subsubsection{Weight, gender, calories, and approach tendencies}

To assess whether the participants particularly displayed an approach tendency for the high calorie food pictures and if so, whether this differs between weight status, we calculated the response tendency per participant and per picture class (high calorie, low calorie, neutral) as the difference in RT between the avoidance response and the approach response. A positive response tendency for high calorie pictures thus reflects more rapid approach than avoidance of high calorie food pictures. These response tendencies served as the dependent variable in a 2 (Group: overweight/obese vs. normal-weight $) \times 2$ (Gender: male vs. female $) \times 3$ (Class: high calorie, low calorie, or neutral) ANCOVA with hunger ratings as covariate.

\subsubsection{Weight, gender, calories, and approach/avoidance}

As the response tendencies in the analysis described above are relative, we conducted two more 2 (Food: high vs. low calorie) $\times 2$ (Group: overweight/obese vs. normal-weight) $\times 2$ (Gender: male vs. female) analyses of covariance with hunger ratings as the covariate and (i) the RTs for having to approach the high and low calorie foods as dependent variable, and (ii) with the RTs for having to avoid these foods as the dependent variable.

\section{Results}

\subsection{Weight, gender, and food approach/avoidance}

In Fig. 1, the mean RTs per assignment are displayed for each group and separately for each gender. When comparing the food avoidance assignment RTs and the food approach assignment RTs, no main effects were found (largest $F[1,83]=2.75, p=.10$ ), but a near significant Group $\times$ Gender interaction was found, $F(1,83)=3.75$, $p=.06, \eta_{\text {partial }}^{2}=.04$. This two-way interaction though is qualified by the overarching Group $\times$ Gender $\times$ Assignment interaction, $F(1,83)$ $=5.09, p=.027, \eta_{\text {partial }}^{2}=.06$. In post-hoc analyses, we examined a potential two-way Group $\times$ Gender interaction for the food approach and food avoidance assignment separately. This interaction was found only for the food avoidance assignment RTs, $F(1,83)=5.16, p=.026$, $\eta_{\text {partial }}^{2}=.06$. We further examined this interaction by testing for a difference in mean RTs between the overweight/obese and normal weight participants for each gender separately by means of independent samples $t$-tests. These tests revealed a significant difference between the overweight/obese men and normal weight men $(t[42]=2.24, p=.03)$, but not between the overweight/obese women and the normal weight women in the sample $(t[42]=1.03$, $p=.31$ ). Overweight/obese male participants were much slower to avoid food stimuli than the normal weight male participants were.

\subsection{Weight, gender, calories, and approach tendencies}

Fig. 2 displays the mean response tendencies for the high calorie foods for each group and separate gender. When comparing the response tendencies for the high calorie foods, low calorie foods and neutral items, we found no main effects or two-way interactions (largest $F=1.71$, $p=.20)$, but this analysis did reveal a significant Group $\times$ Gender $\times$ Class interaction, $F(2,166)=4.59, p=.011, \eta^{2}$ partial $=.05$. We further tested for a Group $\times$ Gender interaction for each picture class. A Group $\times$ Gender interaction effect was found only for the response tendencies for the high calorie foods, $F(1,83)=6.50, p=.013, \eta_{\text {partial }}^{2}=.07$. Further analyses revealed that the female participants show a significant difference between the overweight/obese and normal weight participants, $t(42)=2.59, p=.013$. No such difference was found for the male participants, $t(42)=.95, p=.35$. Considering the response tendencies for the high calorie foods, overweight/obese women show a weaker relative approach tendency than normal weight women do. It is conceivable that dietary restraint underlies this latter finding. Closer inspection of the TFEQ-restraint scores with a 2 (Group: overweight/ obese vs. normal-weight $) \times 2$ (Gender: male vs. female) ANOVA revealed main effects for Group, $F(1,84)=12.35, p=.001$, $\eta^{2}$ partial $=.13$, and for Gender $F(1,84)=7.80, p=.006, \eta^{2}$ partial $=.09$. No Group $\times$ Gender interaction was found, $F<1$. Indeed, the overweight/obese women

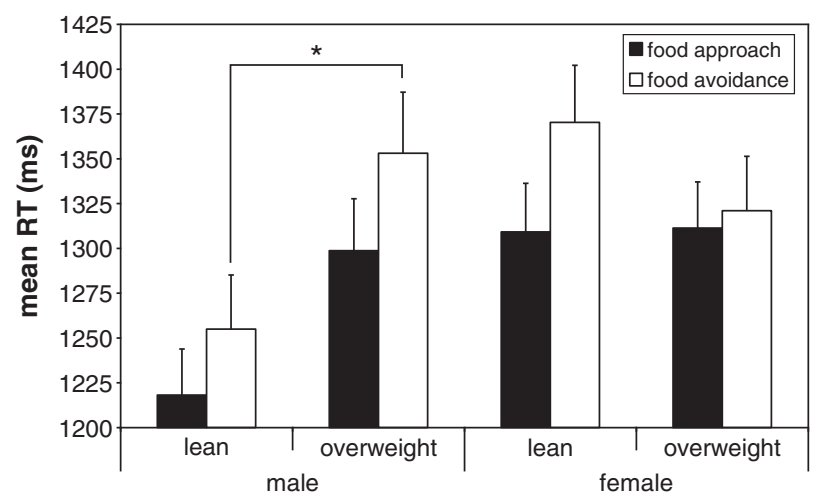

Fig. 1. Mean RT ( + SEM) per response assignment per gender and for each group. Significant $(p<.05)$ post hoc pairwise comparisons are indicated by an asterisk. 


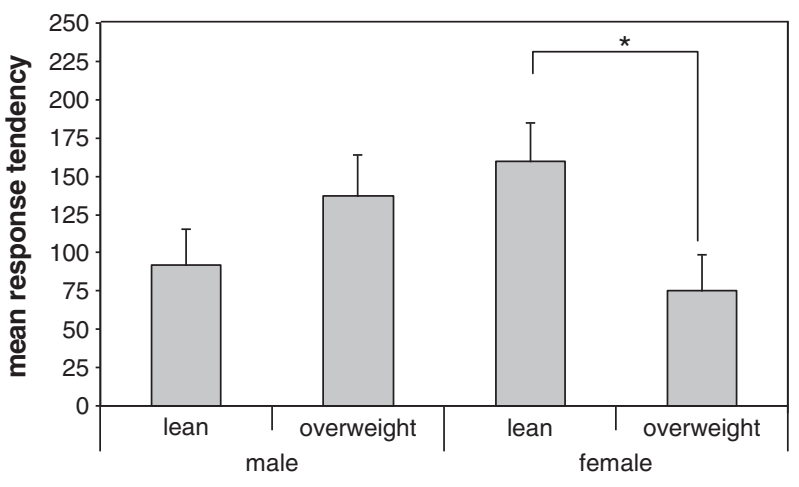

Fig. 2. Mean ( + SEM) response tendency (avoid RT - approach RT) for the high calorie foods per gender and for each group. Significant $(p<.05)$ post hoc pairwise comparisons are indicated by an asterisk.

showed the highest restraint scores $(M=9.0)$, then the overweight/ obese men $(M=6.1)$, then the normal weight women $(M=5.5)$, and the normal weight men showed the lowest degree of restraint $(M=3.9)$.

\subsection{Weight, gender, calories, and approach/avoidance}

When analyzing the absolute approach RTs for the high calorie and low calorie food pictures, an effect for Food was found, $F(1,83)=4.03$, $p=.048, \eta^{2}$ partial $=.05$. Analysis of the absolute avoidance RTs for the food pictures, however, did not reveal any main effects or two-way interaction effects (all $F \mathbf{s}<1$ ) apart from a significant Group $\times$ Gender effect $\left(F[1,83]=4.52, p=.036, \eta^{2}\right.$ partial $\left.=.05\right)$ qualified by a Food $\times$ Group $\times$ Gender three-way interaction, $F(1,83)=4.57, p=.035$, $\eta_{\text {partial }}^{2}=.05$. Post-hoc analyses for each level of the WS-factor Food (high calorie vs. low calorie) revealed a Group $\times$ Gender interaction only for the avoidance of high calorie foods, $F(1,84)=6.50, p=.013$, $\eta_{\text {partial }}^{2}=.07$. Further analyses demonstrated that only among the men in the sample weight status mattered; that is, overweight/obese men are much slower to avoid pictures of high calorie foods than normal weight men are, $t(42)=2.28, p=.028$. Fig. 3 shows the mean avoidance RTs for both the high calorie and low calorie food pictures per gender for each separate group.

\section{Discussion}

In the present study, it was investigated whether overweight/ obese persons, as compared to normal weight controls, show an exaggerated automatic approach tendency for especially high calorie foods. The pattern of results suggests that this is not quite so. Rather, it appears that overweight/obese persons find it harder to avoid especially high calorie foods relative to normal weight individuals.

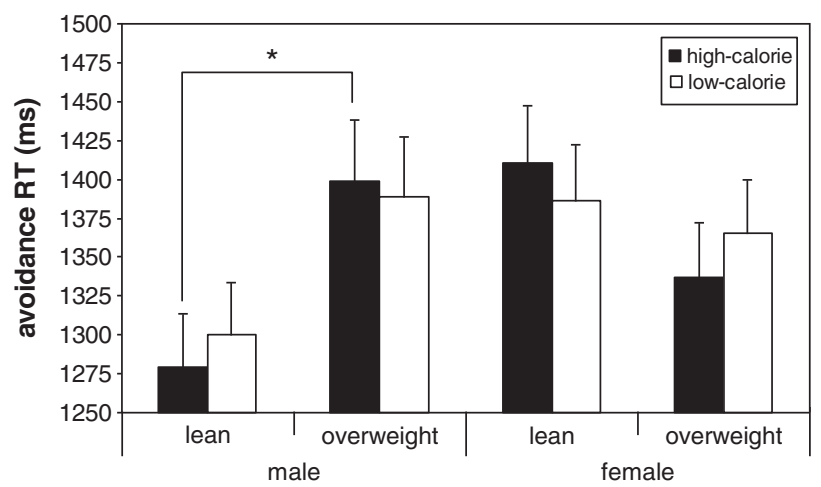

Fig. 3. Mean ( + SEM) avoidance RT for high calorie and low calorie foods displayed per gender and for each separate group. Significant $(p<.05)$ post hoc pairwise comparisons are indicated by an asterisk.
One may speculate that a strong hedonic eating motive makes it very hard to 'walk away' from these foods. But note that this pattern of results was restricted to the male participants.

Considering the response tendencies for the high calorie foods, overweight/obese women - relative to the normal weight women showed a weaker relative approach tendency. Apparently, the overweight/obese women were ambivalent toward high calorie foods, ambivalence expressed as a relatively small approach tendency. This makes sense. When one tries to lose weight, high calorie foods are usually 'forbidden' and thus - given their high TFEQ-restraint score -especially the overweight/obese women displayed a strong avoidance motive when presented with these foods.

In sum, the present study, demonstrates clear gender differences in approach/avoid tendencies (as measured with the SRC task) regarding pictures of high calorie foods. Unlike the men, especially the overweight/obese women in the current study sample seemed to demonstrate ambivalence towards high energy dense food pictures. An ambivalence that appears coupled with restraint. Interestingly, Drapeau et al. (2003) found that a high restraint score in women is associated with weight gain in a 6 year prospective study, but an opposite pattern (i.e. restraint associated with weight loss) was found in men. This finding is difficult to rhyme with the present results. Why would overweight/obese women still tend to overeat on high calorie foods if they demonstrate a clear avoidance intention toward these foods? Perhaps the overeating only occurs in situations where one simply cannot avoid being exposed to palatable food cues. Indeed, such exposure has been shown to induce craving and to promote eating in particularly overweight subjects (see e.g., Jansen et al., 2003). Of course, this account results from post-hoc reasoning and requires further research. It would be interesting to examine whether food cue exposure decreases food approach-avoidance ambivalence.

The present study findings require replication before concluding that overweight/obese men and women have different approachavoidance biases for high calorie food. Although the present study is certainly suggestive of that, it is good to note that we did not assess actual approach or avoidance of real foods. We measured the duration of a response to pictures instead. Further, we only examined a fairly small sample of lean and overweight/obese undergraduate students. Future research is needed to determine whether the present pattern of results extends to a larger and more representative sample of lean and obese individuals. Another limitation of the present study is that the sample was too small to distinguish between overweight and obese participants' performance of the SRC task. It is conceivable that high calorie food approach-avoidance tendencies differ between overweight and obese individuals, but whether that is the case is an empirical matter.

Apart from the limitations outlined above, the current investigation highlights the broader notion that gender differences in eating behaviour need to be accounted for in any model of weight control and/or overeating. Therefore, we like to reiterate the observation and recommendation made by Rolls, Fedoroff, and Guthrie (1991; p. 134): “...most studies of eating behavior do not attempt to distinguish between the sexes. There are, however, several investigations indicating that this should be a part of future work."

\footnotetext{
Role of funding source study.

All the authors declare they did not receive any external funding for the present
}

\section{Contributors}

Author RCH wrote the first draft of the manuscript and all authors contributed to and have approved the final manuscript.

\section{Conflict of interest}

All the authors declare that they have no conflicts of interest. 


\section{References}

Appelhans, B. M. (2009). Neurobehavioral inhibition of reward-driven feeding: Implications for dieting and obesity. Obesity, 17(4), 640-647.

Brignell, C., Griffiths, T., Bradley, B. P., \& Mogg, K. (2009). Attentional and approach biases for pictorial food cues: Influence of external eating. Appetite, 52, 299-306.

De Houwer, J., Crombez, G., Baeyens, F., \& Hermans, D. (2001). On the generality of the affective Simon effect. Cognition \& Emotion, 15, 189-206.

Drapeau, V., Provencher, V., Lemieux, S., Després, J. P., Bouchard, C., \& Tremblay, A. (2003). Do 6-y changes in eating behaviors predict changes in body weight? Results from the Québec Family Study. International Journal of Obesity, 27(7), $808-814$.

French, S. A., Jeffery, R. W., \& Wing, R. R. (1994). Food intake and physical activity: A comparison of three measures of dieting. Addictive Behaviors, 19, 401-409.

Giesen, J. C. A. H., Havermans, R. C., Douven, A., Tekelenburg, M., Nederkoorn, C., \& Jansen, A. (2010). Will work for snack food: The association of BMI and the reinforcing value of snack food. Obesity, 18, 966-970.

Giesen, J. C. A. H., Havermans, R. C., \& Jansen, A. (2010). Substituting snacks with strawberries and sudokus: Does restraint matter? Health Psychology, 29(2), $222-226$.

Giesen, J. C. A. H., Havermans, R. C., Nederkoorn, C., Strafaci, S., \& Jansen, A. (2009). Working harder to obtain more snack foods when wanting to eat less. Behaviour Research and Therapy, 47(1), 13-17.

Havermans, R.C., \& Jansen, A. (in press). Acquired tastes: Establishing food (dis-)likes by flavour-flavour learning. In V. R. Preedy, R. R. Watson, \& C. R. Martin (Eds.), International Handbook of Behavior, Diet, and Nutrition. New York: Springer.

Jansen, A., Theunissen, N., Slechten, K., Nederkoorn, C., Boon, B., Mulkens, S., et al. (2003). Overweight children overeat after exposure to food cues. Eating Behaviors, 4, 197-209.

Jéquier, E. (2002). Pathways to obesity. International Journal of Obesity, 26(Suppl), $12-17$.

Krieglmeyer, R., Deutsch, R., De Houwer, J., \& De Raedt, R. (2010). Being moved: Valence activates approach-avoidance behavior independently of evaluation and approachavoidance intentions. Psychological Science, 21(4), 607-613.

Laessle, R. G., Tuschl, R. J., Kotthaus, B. C., \& Pirke, K. M. (1989). A comparison of the validity of three scales for the assessment of dietary restraint. Journal of Abnormal Psychology, 98, 504-507.
Lowe, M. R., Annunziato, R. A., Markowitz, J. T., Didie, E., Bellace, D. L., Riddell, L., et al (2006). Multiple types of dieting prospectively predict weight gain during the freshman year of college. Appetite, 47(1), 83-90.

Lowe, M. R., \& Levine, A. S. (2005). Eating motives and the controversy over dieting: Eating less than needed versus less than wanted. Obesity Research, 13(5), 797-806.

Olshansky, S. J., Passaro, D. J., Hershow, R. C., Layden, J., Carnes, B. A., Brody, J., et al. (2005). A potential decline in life expectancy in the United States in the 21st century. The New England Journal of Medicine, 352(11), 1138-1145.

Rolls, B. J., Fedoroff, I. C., \& Guthrie, J. F. (1991). Gender differences in eating behavior and body weight regulation. Health Psychology, 10(2), 133-142.

Stice, E., Agras, W. S., \& Hammer, L. D. (1999). Risk factors for the emergence of childhood eating disturbances: A five-year prospective study. The International Journal of Eating Disorders, 25(4), 375-387.

Stice, E., Cameron, R. P., Killen, J. D., Hayward, C., \& Taylor, C. B. (1999). Naturalistic weight-reduction efforts prospectively predict growth in relative weight and onset of obesity among female adolescents. Journal of Consulting and Clinical Psychology, 67(6), 967-974.

Stroebe, W., Papies, E. K., \& Aarts, H. (2008). From homeostatic to hedonic theories of eating: Self-regulatory failure in food-rich environments. Applied Psychology: An International Review, 57(Suppl 1), 172-193.

Stunkard, A. J., \& Messick, S. (1985). The three-factor eating questionnaire to measure dietary restraint, disinhibition and hunger. Journal of Psychosomatic Research, 29(1), $71-83$.

Thewissen, R., Havermans, R. C., Geschwind, N., van den Hout, M., \& Jansen, A. (2007). Pavlovian conditioning of an approach bias in low-dependent smokers. Psychopharmacology, 194(1), 33-39.

Van Gucht, D., Vansteenwegen, D., Van den Bergh, O., \& Beckers, T. (2008). Conditioned craving cues elicit an automatic approach tendency. Behaviour Research and Therapy, 46(10), 1160-1169.

Veenstra, E. M., \& de Jong, P. J. (2010). Restrained eaters show enhanced automatic approach tendencies towards food. Appetite, 55(1), 30-36.

Wing, R., Papandatos, G., Fava, J. L., Gorin, A. A., Phelan, S., McCaffery, J., et al. (2008). Maintaining large weight losses: The role of behavioral and psychological factors. Journal of Consulting and Clinical Psychology, 76(6), 1015-1021.

Yeomans, M. R., Blundell, J. E., \& Leshem, M. (2004). Palatability: response to nutritional need or need-free stimulation of appetite? The British Journal of Nutrition, 92 (Suppl), 3-14. 